14.04

\title{
Влияние концентрации амфифильных молекул неионогенного поверхностно-активного вещества на структуру и гелеобразование в водных дисперсиях
}

\author{
(С) С.А. Алексеева, И.В. Баранец, В.Н. Береснев, Т.А. Надервель, А.Д. Крючков, Т.Е. Суханова \\ Научно-исследовательский институт синтетического каучука им. акад. С.В. Лебедева, \\ 198035 Санкт-Петербург, Россия \\ e-mail: s.alekseeva@fgupniisk.ru
}

Поступило в Редакцию 9 января 2020 г.

В окончательной редакции 9 января 2020 г.

Принято к публикации 17 февраля 2020 г.

\begin{abstract}
Методами вискозиметрии, термогравиметрического анализа, ИК-спектроскопии, фазово-контрастной и поляризационной оптической микроскопии проведено исследование структуры и морфологии водных дисперсий, процесса гелеобразования и межмолекулярных взаимодействий молекул воды с неионогенным низкомолекулярным поверхностно-активным веществом Синтанол АЛМ-10 во всем диапазоне концентраций (от 0 до 100 weight \%). Обнаружен полиморфизм и полидисперсность мицелл Синтанола АЛМ-10. Определен механизм гелеобразования в водных дисперсиях, содержащих от 40 до 70 weight \% амфифильных молекул. Обнаружено, что увеличение концентрации в дисперсиях Синтанола АЛМ-10 сопровождается сначала появлением обратных мицелл поверхностно-активного вещества, затем - последовательным чередованием лиотропных мезофаз, обладающих гексагональной симметрией, и новых форм связанной воды, обусловленных образованием клатратных гидратов. При этом вязкость системы существенно возрастает. При высоких концентрациях Синтанола АЛМ-10 (более 70 weight \%) наблюдаются главным образом обратные мицеллы.
\end{abstract}

Ключевые слова: неионогенное поверхностно-активное вещество, Синтанол АЛМ-10, мицеллы, гелеобразование, поляризационная микроскопия, вискозиметрия, термогравиметрический анализ, ИК-спектроскопия, водные дисперсии, связанная вода.

DOI: $10.21883 /$ JTF.2020.09.49687.2-20

\section{Введение}

Исследованию уникальных свойств воды - важной составляющей биологических сред, необходимой для любых форм жизни, посвящен большой ряд работ известных ученых - В.К. Рентгена, Г. Франка и М. Эванса, Д. Бернала и П. Фаулера, О.Я. Самойлова, Л. Полинга, Робинсона, Г. Немета и Х. Шерага, Г. Френка и В. Уэнома, Г. Стенли, С.В. Зенина, Н. Галамба и многих других [1-26]. Тем не менее единая теория строения воды до настоящего времени не создана.

Исследования поведения молекул воды при взаимодействии с продуктами различной химической природы, в том числе с поверхностно-активными веществами (ПАВ), не теряют своей актуальности [27-39]. ПАВ широко применяются в бумажной, текстильной и пищевой промышленности, в процессах нефтедобычи и обработки металлов, в промышленной стирке и чистке твердых поверхностей, в бытовых моющих и гигиенических средствах - мылах, шампунях, кремах, зубных пастах, в фармакологии и медицине, например, в производстве мягких лекарственных форм, в гидрогелевых повязках для лечения ран и ожогов и т.п. Более того, они незаменимы в различных химических процессах: в качестве среды для разделения веществ в хроматографии [33-35], в качестве эмульгаторов при проведении эмульсионной полимеризации каучуков [36-38] и получения битумных эмульсий для асфальтовых покрытий дорог и кровельных покрытий [39].

Среди промышленно выпускаемых ПАВ Синтанолы - оксиэтилированные спирты - представляют собой смесь полиэтиленглиголевых эфиров, различающихся количеством оксиэтильных групп и величиной гидрофобного радикала. Структурная теория объясняет растворимость полиэтиленгликолей (ПЭГ) в воде близостью расстояния О-O в гексагональной структуре льда $(0.274 \mathrm{~nm})$ и ПЭГ $(0.276 \mathrm{~nm})$, что открывает возможность замещения молекул воды атомами кислорода молекул ПЭГ.

Целью настоящей работы является исследование процесса самоорганизации амфифильных молекул ПАВ и молекул воды в зависимости от концентрации ПАВ в водных дисперсиях, структуры и морфологии формирующихся гелей.

\section{1. Экспериментальная часть}

Объектами исследования являлись водные дисперсии неионогенного низкомолекулярного ПАВ Синтанол АЛМ-10 в широком диапазоне концентраций (от 3 до 95 weight \%) с шагом 3-5 weight \%, полученные при 
Температуры фазовых переходов системы ПАВ/вода, полученные методом ТГА

\begin{tabular}{c|c|c|c}
\hline $\begin{array}{c}\text { Соотношение } \\
\text { ПАВ/вода, } \\
\text { mass. } \%\end{array}$ & $\begin{array}{c}\text { Ступени } \\
\text { разложения, } \\
{ }^{\circ} \mathrm{C}\end{array}$ & $\begin{array}{c}\text { Конечная } \\
\text { температура } \\
\text { разложения, }{ }^{\circ} \mathrm{C}\end{array}$ & $\begin{array}{c}\text { Температуры } \\
\text { фазовых переходов } \\
{ }^{\circ} \mathrm{C}\end{array}$ \\
\hline $0 / 100$ & 90 & 98 & $84-90$ \\
$10 / 90$ & $93-118$ & 391 & $81-359$ \\
$20 / 80$ & $87-160-377$ & 411 & $83-88-388$ \\
$30 / 70$ & $93-103-155-384$ & 425 & $80-101-106-400$ \\
$40 / 60$ & $85-156-252$ & 429 & $83-403$ \\
$50 / 50$ & $94-168-408$ & 433 & $81-108-401-408$ \\
$60 / 40$ & $80-96-172$ & 424 & $85-111-387-403$ \\
$70 / 30$ & $95-109-122-169-249$ & 441 & $72-114-127-249-405$ \\
$80 / 20$ & $78-164$ & 436 & $59-407$ \\
$90 / 10$ & 195 & 431 & $48-124-408$ \\
$100 / 0$ & 197 & 440 & 407
\end{tabular}

комнатной температуре. Перед смешением пасту ПАВ прогревали на водяной бане при температуре $+70^{\circ} \mathrm{C}$ в течение $15 \mathrm{~min}$ с целью устранения предыстории образца (образования кристаллов в процессе хранения). Исходное вещество - Синтанол АЛМ-10 - состоит из амфифильных молекул оксиэтилированного спирта формулы $\mathrm{C}_{n} \mathrm{H}_{(2 n+1)} \mathrm{O}\left(\mathrm{C}_{2} \mathrm{H}_{4} \mathrm{O}\right)_{m}$, где $n=10-13$ длина углеродной цепи, $m=10$ - степень этоксилирования. Молекулярная масса $=362.54 \mathrm{~g} / \mathrm{mol}$. Время хранения дистиллированной воды до приготовления дисперсий не превышало трех суток.

Структурно-морфологические исследования водных дисперсий ПАВ проводили методами фазово-контрастной и поляризационной микроскопии на аналитическом комплексе, включающем исследовательский оптический микроскоп марки Leica DM-2500, цветную цифровую камеру высокого разрешения марки Leica DFC-420, специализированную компьютерную станцию и программное обеспечение Leica Application Suite. Тонкие слои водных дисперсий (,живые капли“) между покровным и предметным стеклами исследованы „на просвет“ в диапазоне длин волн от 200 до $1200 \mathrm{~nm}$, включающем области ближнего ультрафиолета, видимого света и инфракрасного излучения. Основные результаты исследований представлены в виде микрофотографий.

Температуры фазовых переходов водных дисперсий различной концентрации определяли методом термогравиметрического анализа (ТГА) на приборе STA 6000 (Perkin Elmer). Образцы нагревали в интервале температур от 20 до $500^{\circ} \mathrm{C}$ со скоростью $10^{\circ} \mathrm{C} / \mathrm{min}$ при непрерывной фиксации потери массы образца с точностью $\pm 10^{-4} \mathrm{mg}$, изменений теплового потока $[\mathrm{mW}]$ и скорости потери массы $[\mathrm{mg} / \mathrm{min}]$ в зависимости от температуры. Результаты исследования представлены в виде таблицы.

Изменение динамической вязкости водных дисперсий для каждого соотношения ПАВ-вода исследовали при температуре $+25 \pm 0.03^{\circ} \mathrm{C}$ в диапазоне скоростей сдвига от 1.5 до 125 обратных секунд на реометре Discovery Hybrid Rheometer-1, (TA Instruments, USA).
Значения вязкости водных дисперсий при сдвиговом усилии 34.36 обратных секунд использованы для построения графика зависимости величины вязкости дисперсий от концентрации ПАВ. Этот параметр был выбран, поскольку вязкость воды, полученная в данных условиях, соответствует табличным значениям.

ИК-спектры получали на инфракрасном фурьеспекрометре Spectrium 100 (Perkin Elmer, USA), оснащенном приставкой нарушенного полного внутреннего отражения (НПВО) с алмазным кристаллом. Диапазон сканирования: в интервале частот от 650 до $4000 \mathrm{~cm}^{-1}$, разрешение $4 \mathrm{~cm}^{-1}$.

\section{2. Результаты и их обсуждение}

Структурно-морфологические исследования вещества Синтанола АЛМ-10 в исходном состоянии обнаружили присутствие сферических диффузных ассоциатов, образованных путем слияния как прямых, так и обратных мицелл, состоящих из амфифильных молекул ПАВ (рис. $1, a)$, диаметр которых изменяется от 0.3 до $1.3 \mu \mathrm{m}$. На микрофотографиях также хорошо видны цепочечные структуры оптически плотных сферических ассоциатов (рис. 1, $a$ ).

Гидрофильная часть молекулы Синтанола АЛМ-10, содержащая кислородные атомы, обладает повышенной оптической плотностью по сравнению с его гидрофобным „хвостом“, содержащим углеводородные звенья [40]. В прямых мицеллах ПАВ гидрофильные части молекул (с кислородными атомами) расположены по периферии мицелл, поэтому прямые мицеллы проявляют большую оптическую плотность (выглядят темными на микрофотографиях), чем „обратные“ мицеллы (светлые образования округлой формы), в которых гидрофобные фрагменты молекул расположены на поверхности.

С течением времени в образцах Синтанола АЛМ-10 из-за межмицеллярных взаимодействий происходит формирование цилиндрических мицелл и достаточно круп- 
$a$
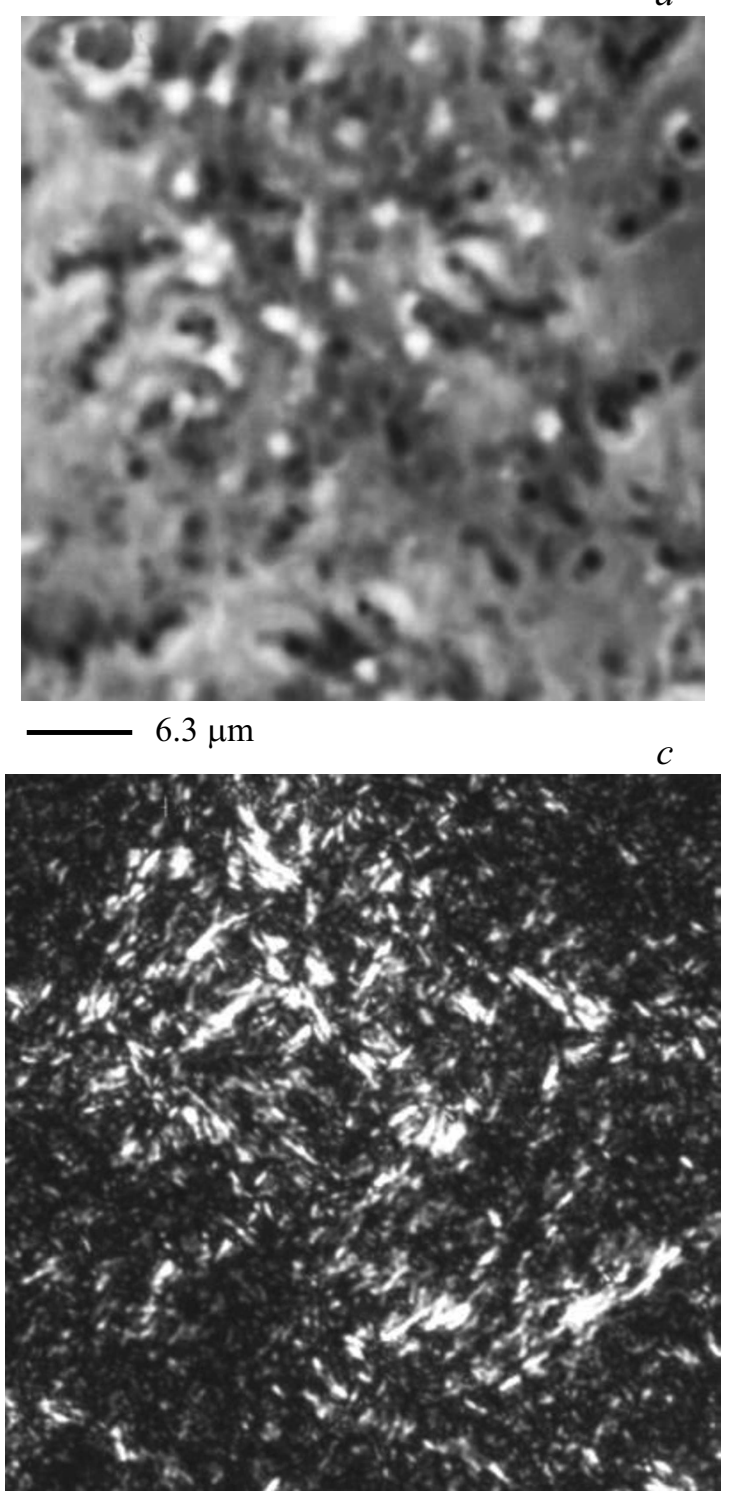

$40 \mu \mathrm{m}$
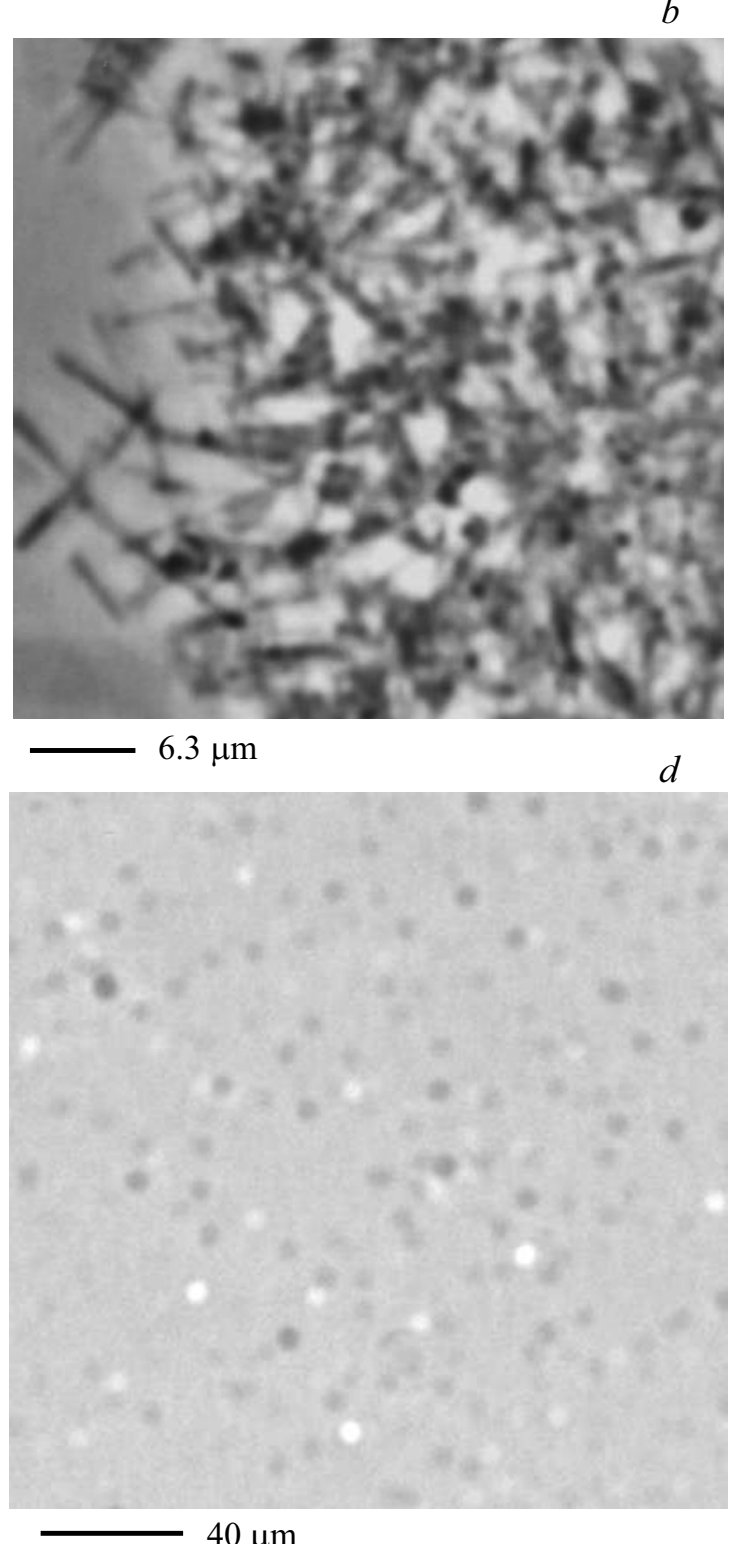

Рис. 1. Микрофотографии исходного Синтанола АЛМ-10 в вязко-текучем состоянии $(a, b, c)$ и водной дисперсии, содержащей 90 weight $\%$ ПАВ $(d)$, полученные в режиме: $a, b, d-$ фазового контраста, $c-$ скрещенных николей.

ных стержнеподобных частиц диаметром от 0.4 до $0.9 \mu \mathrm{m}$ и длиной от 1.8 до $13.5 \mu \mathrm{m}$ (рис. $1, b$ ). После длительного хранения (более трех месяцев при комнатной температуре) исследование в „скрещенных николях“ обнаруживает характерное двулучепреломление, свидетельствующее о формировании дальнего порядка в упаковке макромолекул Синтанола АЛМ-10 как в сферических, так и в цилиндрических надмолекулярных образованиях (рис. 1,c). В водной дисперсии, содержащей 90 weight \% ПАВ (рис. 1,d), обнаружены ассоциаты сферической формы, состоящие как из прямых, так и из обратных мицелл со средним размером $4.5 \mu \mathrm{m}$.

При малых концентрациях ПАВ (до 6 weight \%) в водном растворе существуют только отдельные мицеллы, а надмолекулярные структуры с размерами более $100 \mathrm{~nm}$ отсутствуют. При содержании ПАВ выше 6 weight \% критической концентрации мицеллообразования (ККМ) для Синтанола АЛМ-10, в растворе появляются диффузные сферические ассоциаты прямых мицелл. При содержании ПАВ 10 weight $\%$ их диаметр изменяется в пределах от 200 до $800 \mathrm{~nm}$ (рис. 2,a).

При содержании ПАВ 20 weight \% формируется каркас циклических структур (рис. 2,b), напоминающий микротрабекулярную структуру живой клетки [41]. Диаметр надмолекулярных образований от 0.8 до $2.9 \mu \mathrm{m}$.

При концентрации ПАВ 25 weight \% обнаружено образование нитевидной сетки, имеющей морфологию „жемчужного ожерелья“ [42], состоящего из сферических 

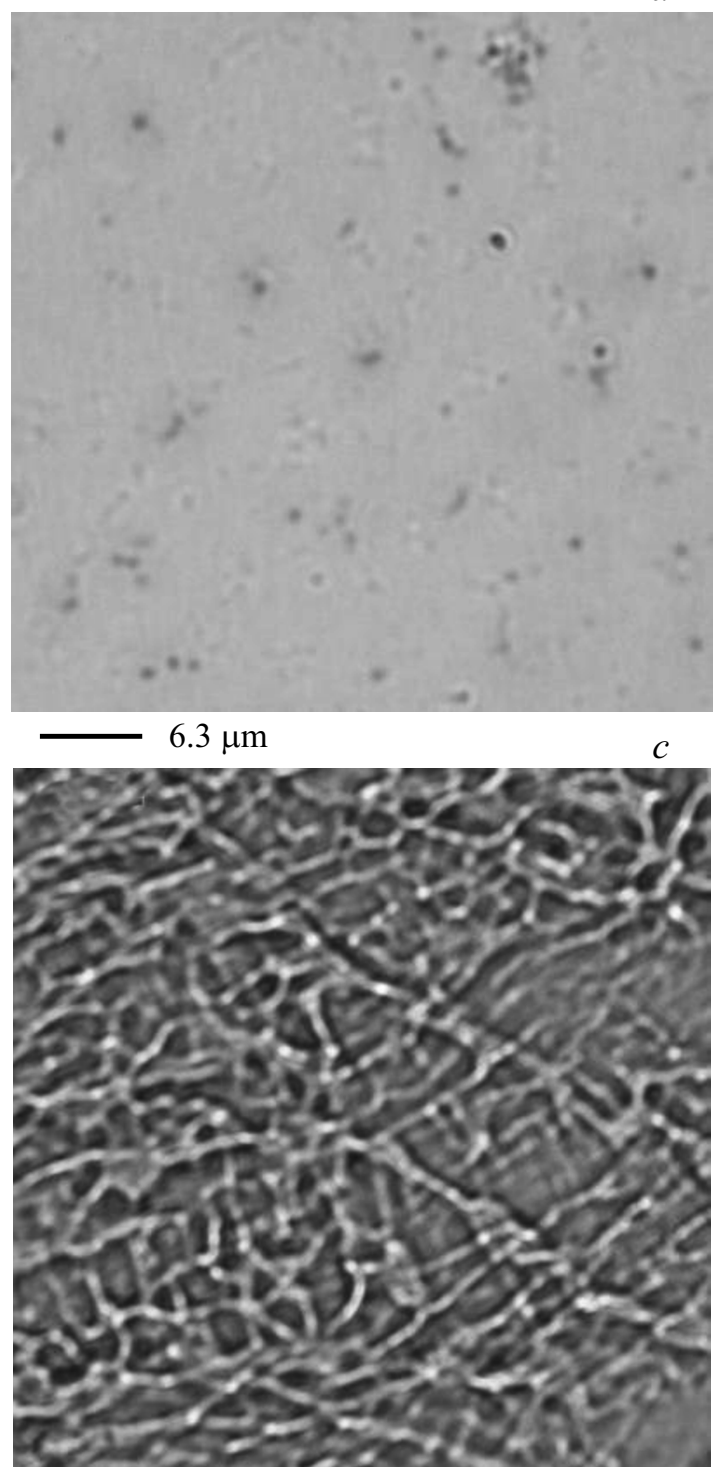

$40 \mu \mathrm{m}$ $b$

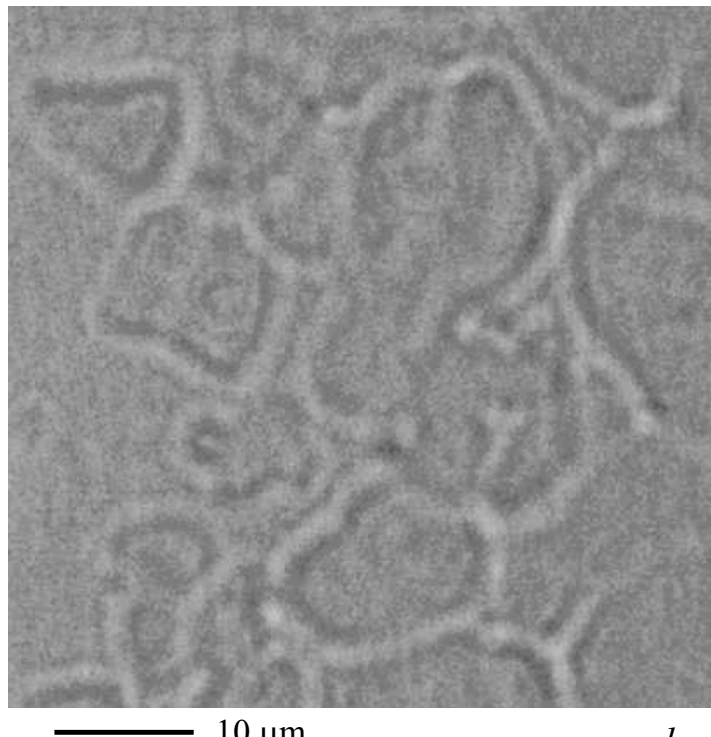

$d$

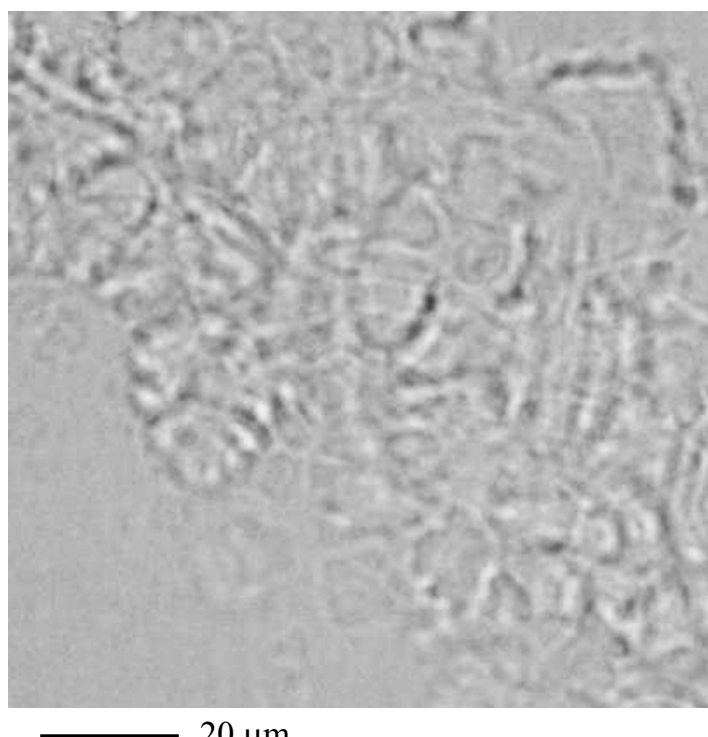

$20 \mu \mathrm{m}$

Рис. 2. Микрофотографии водных дисперсий с содержанием Синтанола АЛМ-10: $10(a), 20(b), 25(c), 30$ weight \% (d), полученные в режиме фазового контраста.

частиц со средним диаметром $6.1 \mu \mathrm{m}$ (рис. 2,c). Этот эффект может быть обусловлен усилением структурирования воды в ближайшем окружении макромолекул ПАВ. При концентрации Синтанола АЛМ-10 30 weight \% в водной дисперсии наблюдается увеличение взаимной упорядоченности макромолекул и формирование надмолекулярных образований, напоминающих дендриты (рис. 2,d).

Однако при исследовании этих составов в режиме „скрещенные николи“ двулучепреломления не выявлено. Надмолекулярные структуры, обладающие двулучепреломлением при исследовании водных дисперсий в режиме „скрещенных николей“, присутствуют в образцах в диапазоне концентраций от 35 до 70 weight \% (рис. 3, 4). При содержании 35 weight \% Синтанола АЛМ-10 в вод- ных дисперсиях формируются кластеры из цилиндрических прямых и обратных мицелл (рис. $3, a, b)$. Размеры зон двулучепреломления при этом составе изменяются от 6.4 до $51.3 \mu \mathrm{m}$, чередуются с аморфными участками и не образуют единого каркаса.

При дальнейшем увеличении концентрации ПАВ до 45 weight \% в жидкой фазе формируется веерная текстура (рис. $3, c$ ). Одновременно происходит интенсивное образование геля. При этом гель характеризуется так называемой „,оманой веерной текстурой“ (рис. 3, $d$ ), имеющей гексагональную надмолекулярную организацию мезофазы [43].

В интервале 50-70 weight \% содержания Синтанола АЛМ-10 наблюдается совершенствование веерной текстуры - увеличиваются размеры мезоморфных доменов 

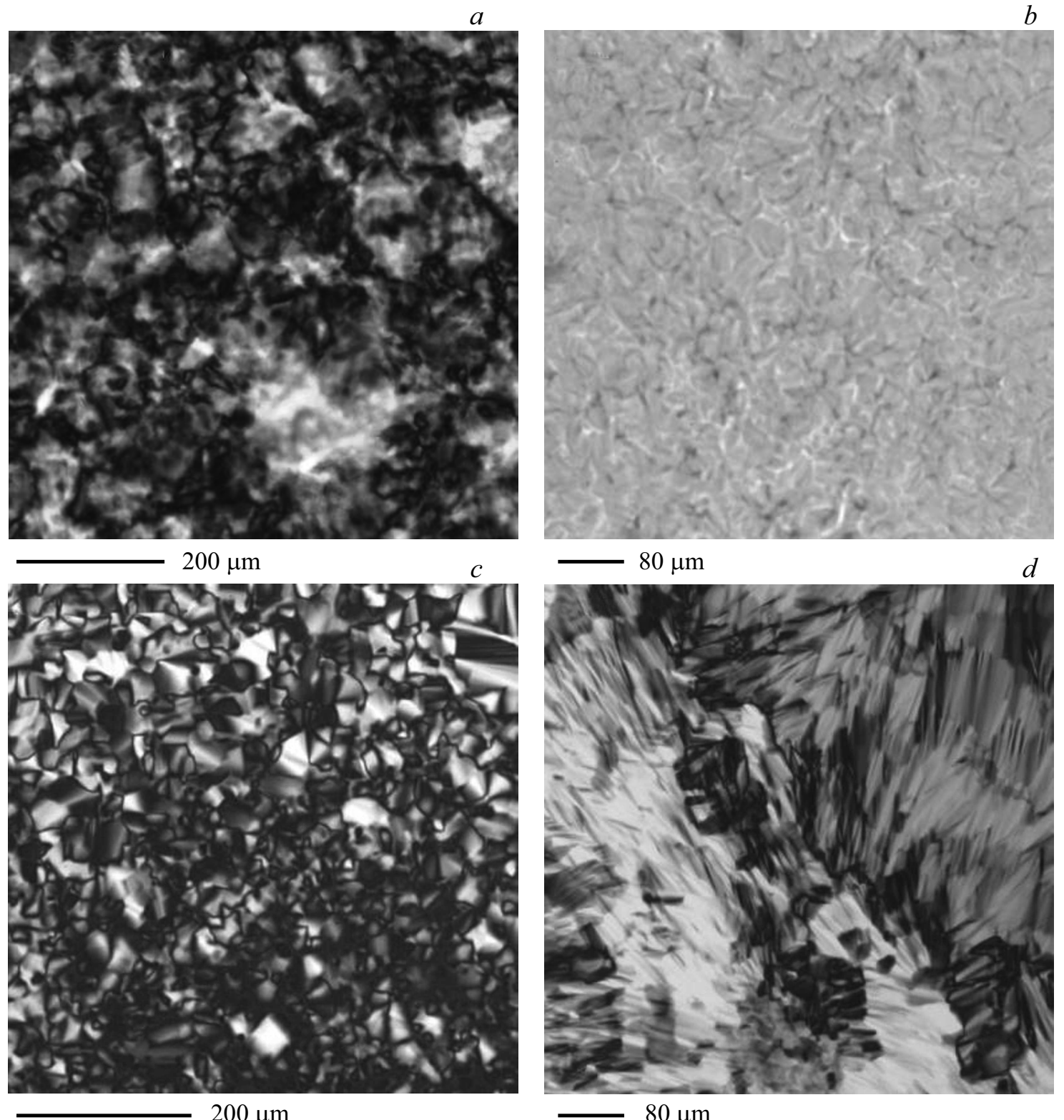

$200 \mu \mathrm{m}$

$80 \mu \mathrm{m}$

Рис. 3. Микрофотографии водных дисперсий с содержанием Синтанола АЛМ-10: 35 (a,b), 45 weight \% (c - жидкая фаза, $d$ - гель), полученных в режимах скрещенные николи $(a, c, d)$, фазовый контраст $(b)$.

с одинаково ориентированными макромолекулярными образованиями (рис. 4, $a-c)$.

При 70 weight \% ПАВ на микрофотографиях хорошо видна слоистая ламеллярная морфология образца (рис. $4, d$ ). Необходимо отметить, что строение пластин варьируется по интенсивности двулучепреломления торцов и поверхностей: видны пластины, в которых двулучепреломление (а значит, и кристаллический порядок) выше на поверхности пластины, при этом ее торец двулучепреломления не имеет. С другой стороны, имеются пластины, в которых торец демонстрирует повышенное двулучепреломление. Вероятно, мы наблюдаем пластинчатые кластеры прямых и обратных мицелл в водном каркасе. Таким образом, в водных дисперсиях с концентрацией ПАВ от 35 до 70 weight \% формируются жидкокристаллические текстуры веерного типа.

При содержании Синтанола АЛМ-10 80-90 weight \% в растворах не обнаружено жидкокристаллической фазы и гелеобразования не происходит. На микрофотографиях показано, что для них характерны диффузные сферические кластеры, состоящие преимущественно из обратных мицелл диаметром от 2.8 до $7.3 \mu \mathrm{m}$ (рис. 1, $d$ ).

С целью определения температур фазовых переходов в растворах Синтанола АЛМ-10 при изменении концентрации водные дисперсии и исходные вещества (дистиллированная вода и Синтанол АЛМ-10) были исследованы методом ТГА. Основные результаты исследований приведены в таблице. 


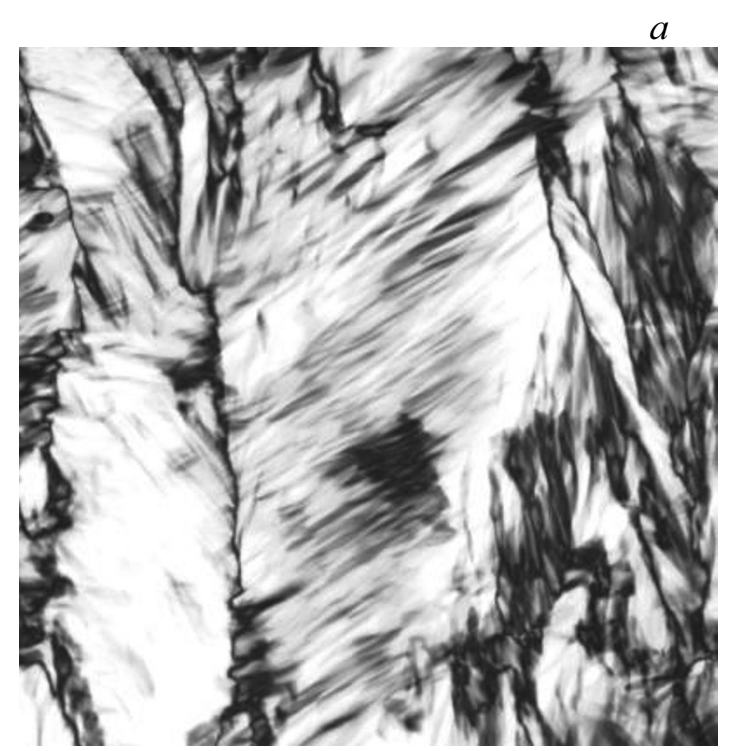

$200 \mu \mathrm{m}$

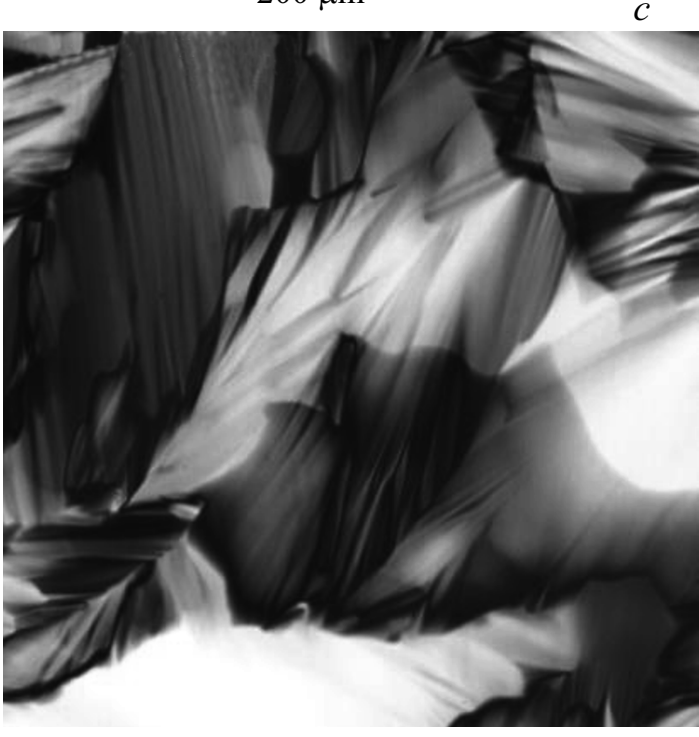

$200 \mu \mathrm{m}$

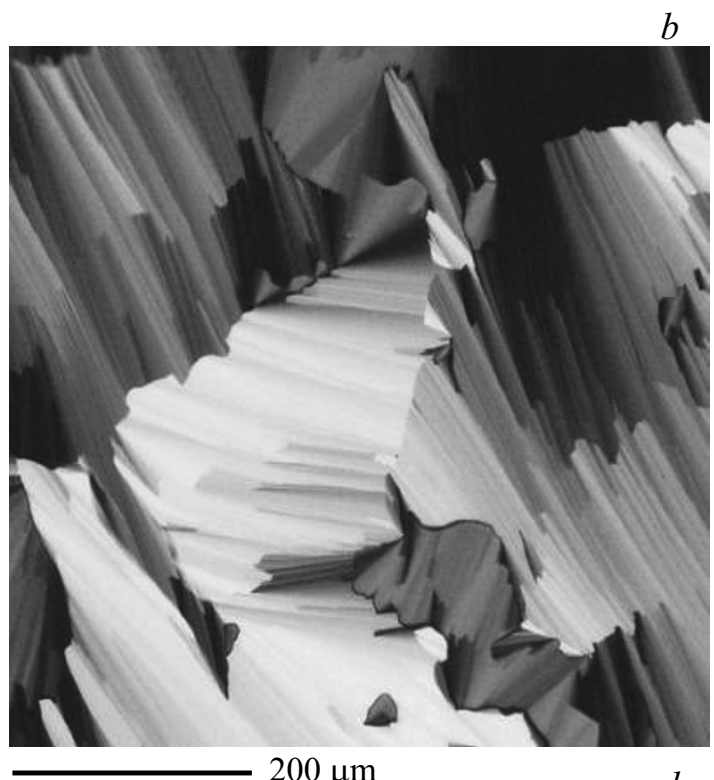

$d$

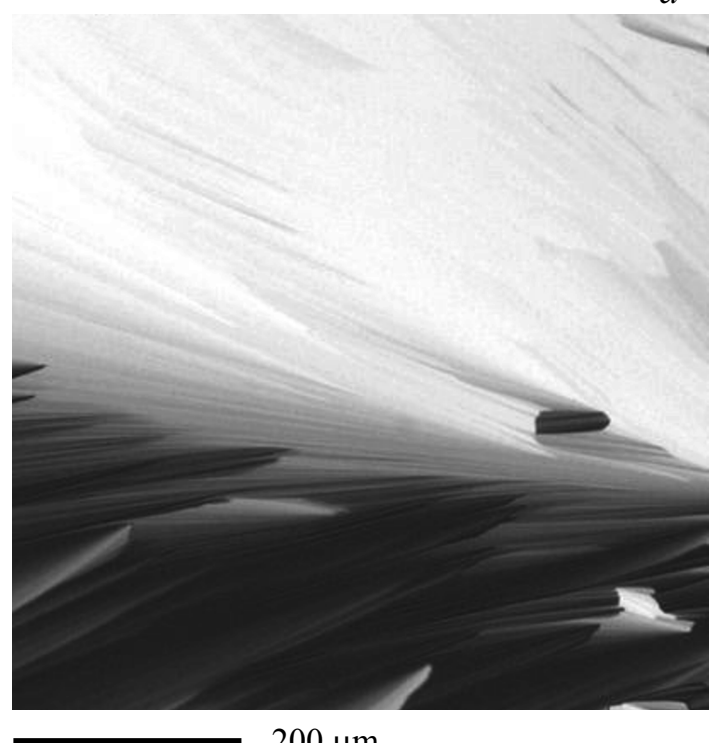

$200 \mu \mathrm{m}$

Рис. 4. Микрофотографии водных дисперсий с содержанием Синтанола АЛМ-10: $50(a), 55(b), 60(c), 70$ weight \% (d), полученные в режиме скрещенных николей.

Из таблицы видно, что исходная дистиллированная вода имеет 2 фазовых перехода, что подтверждает гипотезу двухструктурной модели воды $[1,2,4,5,15,24]$, а Синтанол АЛМ-10 - один, при $407^{\circ} \mathrm{C}$. В водных дисперсиях при концентрации ПАВ до 10 weight \% наблюдается 2 фазовых перехода. При этом существенно (по сравнению с характеристиками для Синтанола АЛМ-10) понижаются конечная температура разложения (на $\left.49^{\circ} \mathrm{C}\right)$ и температура фазового перехода $\left(\right.$ на $\left.48^{\circ} \mathrm{C}\right)$, что свидетельствует о межмолекулярных взаимодействиях молекул ПАВ и воды.

Дальнейшее увеличение концентрации водных дисперсий ПАВ сопровождается сдвигом низкотемпературного фазового перехода: с $84^{\circ} \mathrm{C}$ (для воды) до $48^{\circ} \mathrm{C}$ (в дисперсии с 90 weight \% ПАВ) и высокотемпературного фазового перехода воды в сторону положительных температур - от $+90^{\circ} \mathrm{C}$ до значения $+114^{\circ} \mathrm{C}$ при содержании ПАВ 70 weight \%. Такое поведение растворов свидетельствует о перестройке двух типов надмолекулярных структур молекул воды при взаимодействии с ПАВ.

Интересным является тот факт, что при увеличении концентрации ПАВ от 20 до 70 weight $\%$ количество фазовых переходов в водных дисперсиях увеличивается. При содержании ПАВ 70 weight $\%$ формируется последовательно пять типов мезоморфных структур с разной степенью упорядоченности вследствие взаимодействий молекул воды и Синтанола АЛМ-10, что хорошо согласуется с результатами морфологического исследования этих систем (рис. 2-4). При содержании Синтанола АЛМ-10 в водных дисперсиях 80 и 90 weight \% темпе- 


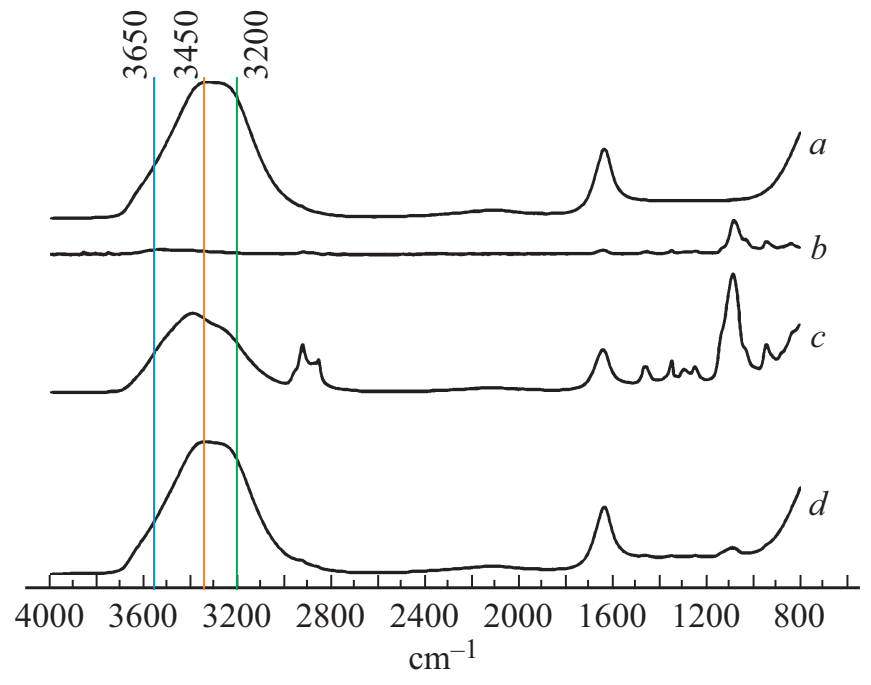

Рис. 5. ИК-спектры: $a-$ дистиллированной воды; $b-$ исходного Синтанола АЛМ-10; $c$ - водной дисперсии, содержащей 60 weight \% Синтанола АЛМ; $d-$ водной дисперсии, содержащей 6 weight \% Синтанола АЛМ-10.

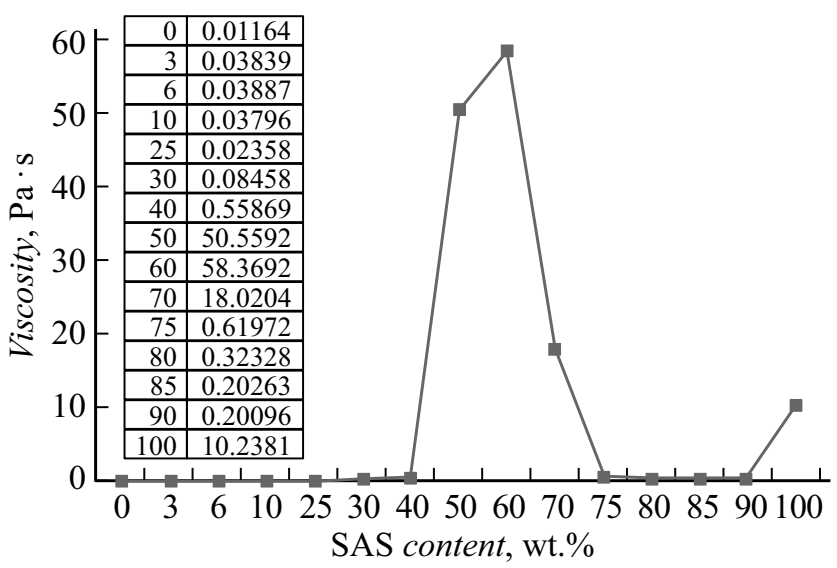

Рис. 6. Зависимость динамической вязкости водных дисперсий Синтанола АЛМ-10 от концентрации при скорости сдвига, равной 34.36 rev.s.

ратурное положение фазовых переходов практически не изменяется.

Изменение сегментальных взаимодействий в водных дисперсиях Синтанола АЛМ-10 оценивали методом инфракрасной спектроскопии. Спектр дистиллированной воды (рис. 5, a) имеет два экстремума в областях 1638 и $3500 \mathrm{~cm}^{-1}$, что согласуется с результатами термогравиметрического анализа. Широкий колоколообразный пик, находящийся в диапазоне частот $3500 \mathrm{~cm}^{-1}$, содержит устойчивые спектральные компоненты, относящиеся к гексагональному льду $\left(3200 \mathrm{~cm}^{-1}\right)$, малоразмерным комплексам - $\left(3450 \mathrm{~cm}^{-1}\right)$ и в меньшей степени мономерам $\left(3650 \mathrm{~cm}^{-1}\right)$.

На спектре исходного Синтанола АЛМ-10 (рис. 5, $b$ ) основной экстремум расположен в области $1100 \mathrm{~cm}^{-1}$. Частотное положение и форма экстремумов ИК- спек- тров исходных компонентов и водной дисперсии при концентрации ПАВ 6 weight $\%$, соответствующей критической концентрации мицеллообразования, совпадают (рис. $5, a, b, d)$. Таким образом, при данной концентрации водных дисперсий не обнаружено межмолекулярных взаимодействий Синтанола АЛМ-10 и воды.

На рис. 5, с представлен ИК-спектр водной дисперсии, содержащей 60 weight \% ПАВ, имеющей гелеобразную консистенцию. Для этой системы обнаружены дополнительные полосы межмолекулярного взаимодействия в областях 2900-3000 и 1200-1500 $\mathrm{cm}^{-1}$ и резкое увеличение интенсивности пика поглощения в области $1100 \mathrm{~cm}^{-1}$. Одновременно изменилась форма колоколообразного пика: заметно снизилась интенсивность поглощения в области $3200 \mathrm{~cm}^{-1}$, характерная для гексагонального льда. Полученные данные свидетельствуют об активном межмолекулярном взаимодействии молекул воды и молекул Синтанола АЛМ-10.

Для каждого соотношения ПАВ-вода были проведены измерения динамической вязкости при различных скоростях сдвига и построены графические зависимости. Для каждого образца были выбраны значения вязкости раствора при скорости сдвига равной 34.36 обратных секунд. По выбранным значениям построен сводный график зависимости вязкости от концентрации ПАВ (рис. 6). Численные значения вязкости при выбранной скорости сдвига приведены в таблице на рис. 6.

Установлено, что вязкость образцов экстремально возрастает в диапазоне концентраций от 40 до 70 weight \% ПАВ. Водные дисперсии имеют гелеобразную консистенцию при содержании Синтанола АЛМ-10 от 45 до 70 weight \%, тогда как веерная мезоморфная текстура с разной степенью упорядоченности обнаружена в интервале концентраций от 35 до 70 weight \% ПАВ.

По нашему мнению, причиной процесса гелеобразования водных дисперсий ПАВ является формирование клатратных гидратов [44], состоящих из каркаса молекул воды, удерживаемых водородными связями вокруг макромолекул Синтанола АЛМ-10.

Анализ существующих в литературе моделей взаимодействия между молекулами воды и амфифильными молекулами ПАВ показал, что наиболее близкой к обнаруженным нами процессам является модель, предложенная Н. Галамба в 2013 году (рис. 7) [22], в которой методом молекулярно-динамического моделирования рассмотрена схема межмолекулярных взаимодействий вблизи гидрофобных веществ. Эта модель является развитием сформулированной ранее Г. Франком и М. Эвансом модели „Айсберга“ [2].

Таким образом, обнаружено взаимное влияние молекул воды и ПАВ на морфологию и степень упорядоченности надмолекулярных образований. Параметром, определяющим формирование прямых либо обратных сферических, либо цилиндрических мицелл, циклических структур или мезоморфных текстур, является соотношение между ПАВ и водой. Это обстоятельство необходимо учитывать, поскольку возможны локальные 


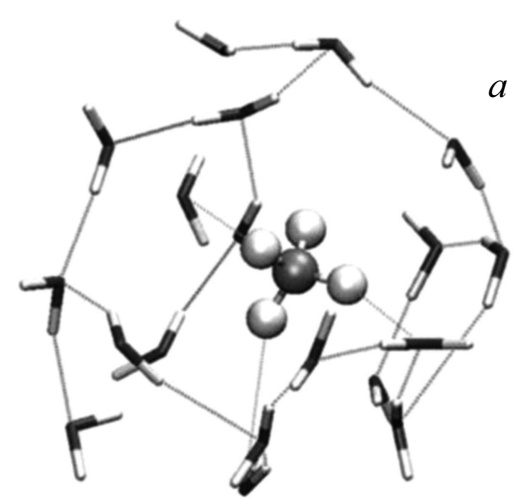

$b$

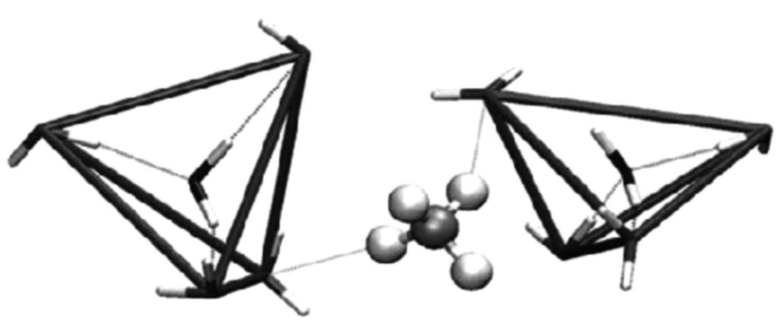

Рис. 7. Водная „клетка“ вокруг молекулы метана, соответствующая молекулам воды в первой гидратной оболочке $(a)$; два водных пентамера, образующих почти совершенные правильные четырехгранники $(b)[22]$.

изменения концентрации ПАВ в водных дисперсиях, например, в адсорбционном слое полимерно-мономерных частиц в процессе эмульсионной полимеризации [37,38], либо на поверхности примесей в многокомпонентных составах другого назначения.

\section{Выводы}

1. Проведено исследование процесса самоорганизации водных дисперсий неионогенного амфифильного поверхностно-активного вещества Синтанол АЛМ-10 при изменении концентраций в широком диапазоне.

2. Методом динамической вискозиметрии обнаружено экстремальное возрастание вязкости водных дисперсий Синтанола АЛМ-10 в диапазоне концентраций от 40 до 70 weight $\%$.

3. Гелеобразование, т. е. формирование пространственного ансамбля взаимоупорядоченных молекул, обнаружено в интервале концентраций 45-70weight \%, а формирование мезоморфных структур - веерной текстуры с различной степенью упорядоченности - в водных дисперсиях ПАВ в интервале концентраций от 35 до 70 weight $\%$.

4. Морфологические исследования показали также, что при малых концентрациях ПАВ (до 30\%) присутствуют преимущественно прямые мицеллы. В интервале концентраций от 35 до 70 weight \% наблюдаются и прямые и обратные мицеллы ПАВ, встроенные в мезоморфные структуры, а при больших концентрациях ПАВ (более 70 weight \%) - преимущественно обратные мицеллы.

5. ТГА и ИК-исследования водных дисперсий Синтанола АЛМ-10 показали, что увеличение концентрации ПАВ сопровождается появлением новых форм связанной воды и образованием клатратных гидратов.

\section{Благодарности}

Авторы выражают благодарность сотруднику ФГУП „НИИСК“ И.В. Кокотину за помощь в получении ИК-спектров.

\section{Конфликт интересов}

Авторы заявляют, что у них нет конфликта интересов.

\section{Список литературы}

[1] Röntgen W.C. // Ann. Phys. Chem. N.F. 1891. P. 91-97.

[2] Frank H.S., Evans M.W. // J. Chem. Phys. 1945. Vol. 13. P. 507.

[3] Самойлов О.Я. Структура водных растворов электролитов и гидратация ионов. М.: АН СССР, 1957. С. 173-180.

[4] Bernal J.D., Fowler R.H. // J. Chem. Phys. 1933. Vol. 1. P. 515.

[5] Malenkov G.G. // J. Phys.: Condens. Matter. 2009. Vol. 21. P. 6.

[6] Pople J.A. // Proc. Roy. Soc. 1951. Vol. 205. P. 163-178.

[7] Pauling L. The Hydrogen Bonding. Ed. D. Hadji. Oxford: Pergamon, 1959. P. 1.

[8] Frank H.S., Wen W.Y. // Discussion Faraday Society. 1957. Vol. 24. P. $133-140$.

[9] Nemethy G., Scheraga H.A. // J. Chem. Phys. 1962. Vol. 36. P. 3382.

[10] Nemethy G., Scheraga H.A. // J. Chem. Phys. 1962. Vol. 36. P. 3401-3417.

[11] Полинг Л. Природа химической связи. М.: Л. Госхимиздат, 1947. C. 116.

[12] Eugene H., Stanley J. // J. Chem. Phys. 1980. P. 73.

[13] Наберухин Ю.И. // Журнал структурной химии. 1992. T. 33. № 6. C. 5-7.

[14] Poole P.H., Sciortino F., Essmann U., Stanley H.E. // Nature. 1992. Vol. 360. P. 324-328.

[15] Jao H., Lee J., Robinson G.W. // J. Am. Chem. Soc. 1990. Vol. 112. P. $5698-5700$.

[16] Urquidi J., Singh S., Cho C.H., Robinson G.W. // Phys. Rev. Lett. 1999. Vol. 83. P. 2348-2350.

[17] Tsai C.J., Jordan K.D. // J. Phys. Chem. 1993. Vol. 97. P. 5208-5210.

[18] Pauling L. // J. Am. Chem. Soc. 1935. Vol. 57. P. 2680-2684.

[19] Наберухин Ю.И. // Соросовский образовательный журнал. 1996. № 5. C. $41-48$.

[20] Stanley H.E. // MRS Bull. 1999. Vol. 24. N 5. P. 22-30.

[21] Канд. дис. Зенин С.В. Структурированное состояние воды как основа управления поведением и безопасностью живых систем: 1999. ГНЦ „ИМБП“. 
[22] Galamba N. // J. Chem. Phys. B. 2013. N 117(7). P. 2153-2159.

[23] Саркисов Г.Н. // УФН. 2006. Т. 176. № 8 С. 833-845.

[24] Malenkov G. // J. Phys.: Condens. Matter. 2009. Vol. 21. N 283101. P. 35.

[25] Соловей А.Б., Лобымев В.И. // ЖФХ. 2006. Т. 80. C. $1778-1783$.

[26] Сидоренко О.Е., Иванова Е.К., Оксенгендлер Б.Л., Тураева Н.Н. // Конденсированные среды и межфазные границы. 2011. T. 13. № 3. С. $341-344$.

[27] Карякин А.В., Кривенцова Г.А. Состояние воды в органических и неорганических соединениях. М.: Наука, 1972. C. 176.

[28] Люк В. Вода в полимерах / Под ред. Г.Е. Заикова. М.: Мир, 1984. C. 555.

[29] Жеребцов Д.А. // Вестник ЮУрТУ, серия „Металлургия“. 2019. T. 19. № 3. С. 66-96.

[30] Нейман Р.Э., Вережников В.Н., Кирдеева А.П. и др. Практикум по коллоидной химии латексов и поверхностноактивных веществ. Учебное пособие для вузов / Под ред. Неймана Р.Э. М.: Высшая школа, 1972. С. 176.

[31] Мчедлов-Петросян О.П., Лебедь А.В., Лебедь В.И. Коллоидные поверхностно-активные вещества. Учебно-методическое пособие. Харьков: ХНУ им. В.Н. Каразина, 2009. C. 72 .

[32] Бибик E.E. Коллоидные растворы и суспензии. Руководство к действию: учебное пособие с компакт-диском. М.: СПб.: Профессия, 2018. С. 252.

[33] Штыков С.Н. // Журнал аналитической химии. 2000. Т. 55. № 7. C. 679-686.

[34] Armstrong D.W., Fendler J.H. // Biochim. Biophis. Acta. 1977. Vol. 478. N 2. P.75-80.

[35] Порозова C.E. Поверхностно-активные вещества в золь-гель технологии: уч. пособие. М.: Пермский нац. исслед. политехн. ун-т. 2014. С. 134.

[36] Канд. дис. Береснев В.Н. Особенности водных растворов неионных эмульгаторов и полистирольных латексов на их основе: Ленингр. технол. ин-т им. Ленсовета. Л. 1966.

[37] Береснев В.Н., Крайник И.И., Баранец И.В. // Сборник тезисов VII Bсеросс. Каргинской конф. „Полимеры - 2017“. 2017. С. 135.

[38] Береснев В.Н., Крайник И.И., Баранеи, И.Б., Агибалова Л.В. // ЖПХ. 2018. Т. 91. № 7. С. 64-72. [Beresnev V.N., Kraynik I.I, Baranetc I.V., Agibalova L.V. // Russ. J. Appl. Chem. 2018. Vol. 91. N 7. P. 64-72].

[39] Ланге К.Р. Поверхностно-активные вещества: синтез, свойства, анализ, применение. СПб.: Профессия, 2016. $239 \mathrm{c}$.

[40] Преч Э., Бюльманн Ф., АФббольтер К. Определение строения органических соединений. М.: Мир, 2006. С. 438.

[41] Веденов А.А., Левченко Е.Б. // УФН. 1983. Т. 141. № 1. C. 3-53.

[42] Теньковцев А.В., Суханова Т.Е., Компан М.Е., Лукошкин В.А., Бурсиан А.Э., Перминова М.П. // ФТТ. 2009. T. 51. Вып. 3. С. 584-589.

[43] Sukhanova T.E., Grigoriev A.I. et. al. // in a Book: Polyimides and Other High Temperature Polymers. Ed. K.L. Mittal, VSP, The Netherlands, 2007. Vol. 4. P. 47-66.

[44] Карапетьяни М.Х., Дракин С.И. Строение вещества: учебное пособие. Изд. 4-е. М.: Книжный дом „Либроком“, 2014. C. 312. 